\title{
MiR-489-3p modulates cell proliferation and apoptosis in cerulein-induced acute pancreatitis by targeting $\mathrm{X}$-linked inhibitor of apoptosis protein
}

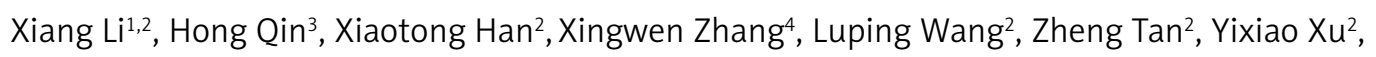
Zhanhong Tang ${ }^{1}$

${ }^{1}$ Critical Care Unit, The First Affiliated Hospital of Guangxi Medical University, Nanning, Guangxi, P.R. China

2Emergency Department (one) of Hunan Provincial People's Hospital, Changsha, Hunan, P.R. China

${ }^{3}$ Xiangya School of Public Health, Central South University, Changsha, Hunan, P.R. China

${ }^{4}$ Emergency Department (three) of Hunan Provincial People's Hospital, Changsha, Hunan, P.R. China

Submitted: 15 August 2019

Accepted: 2 February 2020

Arch Med Sci 2020

DOI: https://doi.org/10.5114/aoms/117736

Copyright $2020 @$ Termedia \& Banach

\section{Abstract}

Introduction: This study aims to explore the effect and mechanism of miR489-3p on the proliferation and apoptosis of pancreatic acinar cells in acute pancreatitis (AP).

Material and methods: $X$-linked inhibitor of apoptosis protein (XIAP) and miR-489-3p expression in serum of AP patients, pancreatic AR42J cells, and rat $A P$ tissues were measured using quantitative reverse transcription polymerase chain reaction and western blot. The effect of miR-489-3p on proliferation and apoptosis was determined by MTT assay and flow cytometry. The relationship between XIAP and miR-489-3p was verified using luciferase assay RNA immunoprecipitation assay. Histological changes in rat pancreatic tissues were observed via haematoxylin and eosin staining.

Results: Measurement of miR-489-3p and XIAP expressions in AP patients revealed a negative correlation between miR-489-3p and XIAP. Increased miR-489-3p expression in AP patients indicated a poor prognosis. Cerulein was used to induce AP in AR42J cells and standard deviation rats. Experiments in cells and AP rat models showed that miR-489-3p can increase cell apoptosis and inhibit cell proliferation by regulating XIAP, as shown by elevated expressions of pro-apoptotic proteins (p53 and Bax) and decreased expression of proliferation indicator (Ki-67) after transfection of miR-489$3 p$ mimics. Meanwhile, knockdown of miR-489-3p abrogated the inhibitory effects of miR-489-3p on cell proliferation and the promotion on cell apoptosis. Luciferase assay and RNA immunoprecipitation assay confirmed that XIAP can directly bind miR-489-3p.

Conclusions: We concluded that miR-489-3p modulates cell proliferation and apoptosis in AP by targeting XIAP. Given that high expression of miR489-3p in AP indicated poor prognosis, it raises the possibility that miR489-3p might be a novel and valuable therapeutic target and a prognosis indicator for AP.

Key words: X-linked inhibitor of apoptosis protein, miR-489-3p, acute pancreatitis, cell proliferation, cell apoptosis, cerulean.
Corresponding author:

Zhanhong Tang

Critical Care Unit

The First Affiliated Hospital of Guangxi Medical

University

No. 6, Shuangyong Road

Nanning, Guangxi 530021, P.R. China

Phone: +86-13978816316

E-mail: tangzhanhong139@

sina.com 


\section{Introduction}

Acute pancreatitis (AP) is a potentially fatal disease ranging from mild acute pancreatitis to severe acute pancreatitis (SAP) [1]. Although knowledge on the exact pathophysiology of AP is limited, it is widely accepted that AP is an inflammatory consequence resulting from autodigestion of local tissues caused by the activation of digestive enzymes [2]. Walled-off pancreatic necrosis is observed in approximately $15 \%$ of patients with severe AP [3]. The overall mortality of this disease is less than $5 \%$, while that for SAP can increase to $20-30 \%$ in the case of pancreatitis necrosis and multi-organ failure [4-6]. Persistent organ failure and infected pancreatic necrosis are not only considered as major contributors to high mortality, but also serve as predictors for poor prognosis [7]. Despite the fact that the serum level of pancreatic enzymes remains the gold standard for AP diagnosis, early assessment for AP severity is crucial for ensuring rapid and appropriate treatment for SAP patients so as to achieve better prognosis [8]. Despite the fact that IL-6, c-reactive protein (CRP), and Atlanta classification show great potential in assessing AP severity, a consensus on a gold standard for prognostic evaluation of AP has not been reached [6, 9-11]. To advance the therapeutic strategy, novel biomarkers for AP are urgently needed to facilitate the management and delivery of care for AP patients.

MicroRNAs (miRNAs) have recently been implicated in various pancreatic biological activities by regulating cell development, pancreas regeneration, and islet functions [12]. Dysregulated expressions of miRNAs (miR-205, miR-210, miR-492, and miR-1247) in pancreatic liquid were proven to be associate with prognosis of patients with pancreatic ductal adenocarcinoma $[13,14]$. Also, miRNAs were reported to be associated with malignant tumours and inflammation, as shown by a previous study demonstrating that miR-146a could inhibit inflammation response while miR-155 could accelerate inflammation response in mice models $[15,16]$. MiR-489, an miRNA related with the carcinoma process, can either function as an oncogene or an anti-oncogene through implication in cell development and progression [17]. MiR-489 was also believed to be implicated in inflammation response because migration and metastasis of pancreatic ductal adenocarcinoma cells were promoted in response to repression of miR-489 through KRAS-induced inflammatory signalling [18]. In addition, many miRNAs are supported to serve as biomarkers for diagnosis and severity of $A P$, including miR-92b, miR-10a, miR-7, and miR551b-5p [19], while limited information is available for miR-489-based therapy of AP and the clinical significance and underlying mechanisms of miR-489 in AP remain a mystery.
X-linked inhibitor of apoptosis protein (XIAP) is a member of the inhibitor of apoptosis protein family [20]. It is composed of a ubiquitin-binding domain, three baculovirus inhibitors of apoptosis protein repeat domains, and a C-terminal really interesting new gene (RING) domain with E3 ubiquitin ligase activity [21]. X-linked inhibitor of apoptosis protein was previously shown to be involved in inflammasome activation in non-ocular cells [22]. Besides, down-regulation of GRP78 and XIAP is correlated with apoptosis through negatively regulating caspase activation during cerulein-induced AP in rats [23]. Nevertheless, the upstream of XIAP in AP was unclear and the mechanism of down-regulation of XIAP in AP also needs to be clarified.

In this study, we aimed to explore the possible effect and the potential mechanism of miR-489 into AP. The expression of miR-489 was detected separately in serum of AP patients, in mice, as well as in AP cell lines. In this study, we showed that XIAP is a target gene of miR-489 in AP; therefore, we hypothesise that miR-489 may serve as a regulator in AP by down-regulating its target gene XIAP, to regulate cell proliferation and cell apoptosis.

\section{Material and methods}

\section{Material}

A total of 51 clinical serum samples were obtained from AP patients admitted to Hunan Provincial People's Hospital between 2014 and 2015. The included AP patients (male proportion of $62.7 \%$ ) ranged from 22 to 78 years old with a median age of 51 years. Meanwhile, serum samples of 40 non-AP patients (patients with bile duct stone) in our hospital during the same period were included as controls. The controls (male proportion of $67.5 \%$ ) had a median age of 49 years ranging from 24 to 76 years. The study was conducted in accordance with the Declaration of Helsinki. The study protocol was approved by the Ethics Committee of Hunan Provincial People's Hospital. All the patients provided their written informed consent.

\section{Cell culture}

Rat pancreatic acinar cells, AR42J cell lines, were purchased from the American type culture collection, and human embryonic kidney 293 (HEK-293) cell lines were brought from the Cell Culture Centre from the Institute of Basic Medical Sciences of the Chinese Academy of Medical Sciences. The cell lines were cultured strictly according to instructions. Rat pancreatic AR42J cells in logarithmic growth phase subjected to cerulein treatment were transfected with 100 nM of miR-489-3p mimic, miR-489-3p inhibitor, miR-489-3p mimic negative control (mimic 
NC), or miR-489-3p inhibitor negative control (inhibitor NC) using a lipofectamine 2000 transfection kit (Invitrogen, USA). Cell transfection was performed based on the instructions of the lipofectamine 2000 kit. Transfected cells were cultured in serum-freed Dulbecco's modified eagle medium (DMEM) for eight hours. After that DMEM culture medium was replaced by DMEM medium with $10 \%$ foetal bovine serum for subsequent culture in an incubator with $5 \% \mathrm{CO}_{2}$ and $95 \%$ humidity at $37^{\circ} \mathrm{C}$ for $48 \mathrm{~h}$, RNA was harvested, and protein was extracted for subsequent experiment.

\section{Real-time reverse transcription polymerase chain reaction}

AR42J cells or pancreatic tissues were dissolved in $1 \mathrm{ml}$ of Trizol (Invitrogen) to extract RNA according to Trizol instructions. After quantification, RNA was reversed into cDNA. Polymerase chain reaction (PCR) reaction system was prepared according to instruction of the quantification PCR kit (Takara, Dalian, China). All real-time quantitative reverse transcription PCR (RT-PCR) reactions were performed on an $A B I 7500$ instrument (Applied Biosystems). The reaction condition includes pre-denature of $10 \mathrm{~min}$ at $95^{\circ} \mathrm{C}, 40$ cycles of denature of $10 \mathrm{~s}$ at $95^{\circ} \mathrm{C}$, annealing of $20 \mathrm{~s}$ at $60^{\circ} \mathrm{C}$, and extension of $34 \mathrm{~s}$ at $72^{\circ} \mathrm{C}$. The primer sequences provided by GeneWiz (GeneWiz, Suzhou, China) were as follows: RT-PCR primers for XIAP (XIAP-F: 5'-TGGCAGATTATGAAGCACGGATC', XIAP-R:5'-AGTTAGCCCTCCTCCACAGTGA-3'), RT primers for miR489-3p (5'-CTCAACTGGTGTCGTGGAGTCGGCAATTCAGTTGAGAGCTGCCGT-3'), PCR primers for miR489-3p (miR-489-3p-F: 5'-ACACTCCAGCTGGGGTGACATCACATA-3', miR-489-3p-R: 5'-TGGTGTCGTGGAGTCG-3'), PCR primers for GAPDH (GAPDP-F: 5'-GAAGGTGAAGGTCGGAGTC-3', GAPDH-R: 5'-GAAGATGGTGATGGGATTTC-3').

\section{MTT assay}

AR42J cells in logarithmic growth phase were grouped into a blank control group (subjected to normal saline treatment) and a cerulein group (subjected to cerulein treatment). Cells in the cerulein group were subjected to $10^{-7}$ of cerulein (Sigma-Aldrich, St. Louis, MO) for $3 \mathrm{~h}$ before plasmid transfection. Cells were counted after plasmid was transfected for, respectively, $24 \mathrm{~h}, 48 \mathrm{~h}$, $72 \mathrm{~h}$, and $96 \mathrm{~h}$. Cell suspensions $\left(100 \mu \mathrm{L}, 10^{4}-10^{5}\right.$ cells) were plated into 96 -well plates and cultured at $37^{\circ} \mathrm{C}$ with $5 \% \mathrm{CO}_{2}$. Three replicate wells were set for each group. Then $20 \mu \mathrm{L}$ of MTT $(5 \mathrm{mg} / \mathrm{mL}$, Sigma) was added into each well for further incubation. About $4 \mathrm{~h}$ later, the culture medium was removed, and each well was given an additional $150 \mu \mathrm{L}$ of DMSO and gently shaken for $10 \mathrm{~min}$.
Then the $495 \mathrm{~nm}$ optical density $\left(\mathrm{OD}_{495}\right)$ was read on a microplate reader. Each experiment was repeated three times.

\section{Western blot}

Rat pancreatic tissues were prepared and subjected to cell lysis with $100 \mu \mathrm{L} / 50 \mathrm{~mL}$ lysis buffer on ice for $30 \mathrm{~min}$ after phosphate-buffered saline (PBS) washing three times. Then the proteins were centrifuged at $4^{\circ} \mathrm{C}$ at $12,000 \mathrm{rpm}$ for $10 \mathrm{~min}$ to obtain the supernatant. Then the supernatant was collected into $0.5 \mathrm{~mL}$ centrifuge tubes for storage at $-20^{\circ} \mathrm{C}$ or quantitation using a BCA kit. Loading buffer $(6 \times \mathrm{SDS})$ was added at $100^{\circ} \mathrm{C}$ before total proteins were separated by SDS electrophoresis and blotted to membrane for $1.5 \mathrm{~h}$ using $4^{\circ} \mathrm{C}$ pre-cold transfer buffer. Membranes were then blocked with 5\% skimmed powder for $1 \mathrm{~h}$ and incubated with primary antibodies for XIAP (ab14334s), $\beta$-actin (ab4970s), p53 (ab2527S), and $\operatorname{Bax}(a b 5023 S)$ (1:1000; cell signalling technology) at $4^{\circ} \mathrm{C}$ overnight. After $3 \times 10$ min washes in TBST, membranes were incubated with secondary antibodies of goat anti-rabbit lgG (1:5000, Beijing ComWin Biotech Co., Ltd, Beijing, China) for $2 \mathrm{~h}$. Then membranes were washed in TBST and visualised for expressions of XIAP, $\beta$-actin, p53, and Bax.

\section{Flow cytometry}

Cerulein-induced AR42J cells were washed with PBS and digested by pancreatic enzymes before centrifugation at $1000 \mathrm{rpm}$ for $5 \mathrm{~min}$ at room temperature. Abandon the supernatant and re-suspend the cells in PBS. Cells were centrifuged at $1000 \mathrm{rpm}$ at room temperature for $5 \mathrm{~min}$ with supernatant removed and $490 \mu \mathrm{L}$ of pre-cold $1 \times$ binding buffer (cell concentration of $10^{5}-10^{6} / \mathrm{ml}$ ) was added. Subsequently, $5 \mu \mathrm{L}$ of Annexin V-FITC and $5 \mu \mathrm{L}$ of PI were added into the cell suspension with gentle shaking for subsequent incubation on ice for 10 min without light exposure. Flow cytometry (FCM) was applied to measure cell apoptosis.

\section{Enzyme-linked immunosorbent assay}

After AR42J cells were treated with cerulein for $24 \mathrm{~h}$, serum levels of serum amyloid A (SAA), IL-1 $\beta, I L-6$, and CRP were detected using an enzyme-linked immunosorbent assay kit (R\&D, USA) according to the manufacturer's instructions.

\section{Determination of serum amylase and lipase levels}

After 12,24 , and $48 \mathrm{~h}$ of rat model establishment, the level of serum amylase was examined using Olympus Au2700 system, and lipase lev- 
el was measured by a modular P800 automatic biochemical analyser (Roche Diagnostics $\mathrm{GmbH}$, Mannheim, Germany). The detection was measured in strict accordance with the requirements.

\section{Luciferase reporter gene assay}

The binding site of miR-489-3p and XIAP was predicted by online software - Target Scan and Starbase. The mutant sequence and wild sequence of the bind site were designed and cloned into Promega vector. The designed sequences were co-transfected with miR-489-3p mimics or miR-489-3p negative control into HEK-293 cells. After transfection for $48 \mathrm{~h}$, a luciferase kit (purchased from YuanPingHao Bio, Beijing, China) was used to measure the fluorescence intensity.

\section{Co-immunoprecipitation and immunoblotting}

Human embryonic kidney 293 cells transfected with miR-489-3p mimics were washed thrice in PBS at $4^{\circ} \mathrm{C}$ and incubated with radioimmunoprecipitation assay (RIPA) buffer (Thermo) supplemented with protease inhibitor at $4^{\circ} \mathrm{C}$ for $30 \mathrm{~min}$. Then cell lyses were subjected to centrifugation at $1,2000 \times \mathrm{g}$ at $4^{\circ} \mathrm{C}$ for $15 \mathrm{~min}$. The supernatant was removed to measure the protein concentration. Total cell protein $(200 \mu \mathrm{g})$ was diluted to a concentration of $2 \mu \mathrm{g} / \mu \mathrm{L}$ using RIPA buffer supplemented with protease inhibitor (Merck). After that, $10 \mu \mathrm{L}$ of anti-XIAP antibody was added to the cell lysis at $4^{\circ} \mathrm{C}$ in a rotator overnight, and the same volume of anti-lgG (Invitrogen) was used as negative control. Then $30 \mu \mathrm{L}$ of Protein G Agrose was added in cell lysis at $4^{\circ} \mathrm{C}$ in a rotator overnight before centrifugation at $1,4000 \mathrm{~g}$ for $1 \mathrm{~min}$. Supernatant was removed and RIPA Buffer washing was carreid out 3 to 5 times prior to reaction with $30 \mu \mathrm{L}$ of $2 \times$ Laemmli sample buffer in metal bath $\left(100^{\circ} \mathrm{C}, 5 \mathrm{~min}\right)$. The proteins were centrifuged to obtain the supernatant. The immunoblotting was verified by western blot.

\section{Immunoprecipitation reverse transcription polymerase chain reaction}

The protein-RNA complexes binding to beads were re-suspended using $200 \mathrm{uL}$ RIPA buffer in a metal bath $\left(70^{\circ} \mathrm{C}, 45 \mathrm{~min}\right)$. Then $500 \mu \mathrm{L}$ of TRIzol (Invitrogen) was added for RNA extraction. RNA was obtained for further PCR.

\section{Establishment of cerulein-induced acute pancreatitis model}

Standard deviation (SD) rats $(n=36$, aged $6-8$ weeks, weighing 180-220 g) were provided by Laboratory Animal Centre of the Fourth Military
Medical University. The rats were habituated to environment for one week with free access to food and water and randomly classified into a normal group $(n=8)$, a model group $(n=8)$ and an experimental group (10 rats for miR-489-3p inhibitor group and 10 rats for inhibitor NC group). Rats in the normal group were subjected to intraperitoneal injection of normal saline $(0.2 \mathrm{ml} / \mathrm{h})$ while rats in the model group and experimental group were intraperitoneal injected with cerulein $(50 \mu \mathrm{g} /$ $\mathrm{Kg} \mathrm{h}$ ). Intraperitoneal injection was performed for continuous seven times, for $1 \mathrm{~h}$ each time. Rats in the model group and normal group were fed for another week before being sacrificed for sample collection. Meanwhile, rats in the experimental group were injected with miR-489-3p inhibitor or inhibitor NC via tail vein $12 \mathrm{~h}$ before being sacrificed. Pancreatic tissues from rats in experimental group and model group were collected at the same time. This experiment was approved by the Local Ethical Committee of Hunan Provincial People's Hospital. All efforts were made to minimise the pain of the animals.

\section{Haematoxylin and eosin staining}

Pancreatic tissues were fixed in $4 \%$ paraformaldehyde overnight and subjected to gradient ethanol dehydration using a biological tissue automatic dehydrator. Then tissues were subjected to permeabilisation by xylene and sliced after embedding. Haematoxylin and eosin or Fluor-Jade B was used for tissue staining. Slices were mounted by neutral balsam or DPX Mountant.

\section{Immunohistochemistry}

Slices were boiled in EDTA antigen retrieval buffer $(\mathrm{PH}=9.0)$ for $10 \mathrm{~min}$ and washed in phosphate-buffered saline three times. Hydrogen peroxide (3\%) was added for incubation for $10 \mathrm{~min}$ to block activity of endogenous peroxidase. Phosphate-buffered saline washing was carried out three times. Reactions were terminated at $0.5 \mathrm{~h}$ using serum. Then primary antibodies for XIAP (1:100, Santa Cruz) and Ki-67 (1:100, Santa Cruz) were prepared using $50 \mu \mathrm{L}$ of blocking buffer and incubated with slices at $4^{\circ} \mathrm{C}$ overnight. Secondary antibodies were added for incubation for $0.5 \mathrm{~h}$ after PBS rinsing three times. After the slices were washed in PBS three times, DAB was used for colour development and haematoxylin for staining in the cell nucleus for $3 \mathrm{~min}$. Then the slices were subjected to $1 \%$ hydrochloride and ethanol treatment for $1-3 \mathrm{~s}$, washed in running water, $0.6 \%$ ammonium hydroxide and wash in running water. Dehydration was accomplished in increasing concentrations of ethanol and cell permeabilisation by xylene. Slices were mounted by neutral balsam. 
Tissues were observed and photographed under a light microscope.

\section{Statistical analysis}

Data were processed using SPSS17.0 (SPSS, Chicago, IL, USA) and GraphPad Prism 6.0. Comparisons between two groups were analysed using $\mathrm{T}$ test, while multi-group comparisons were performed using one-way analysis of variance. Categorical data were analysed using $\chi^{2}$ test. The Kaplan-Meier method was used to assess the overall survival rate, and differences were assessed using the log-rank test. The correlation of miR-489-3p and XIAP was analysed by Spearman rank correlation coefficient. $p<0.05$ was consid-

A

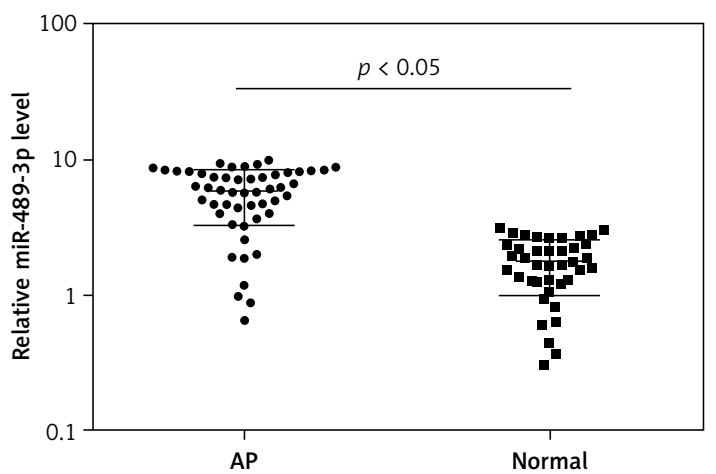

C

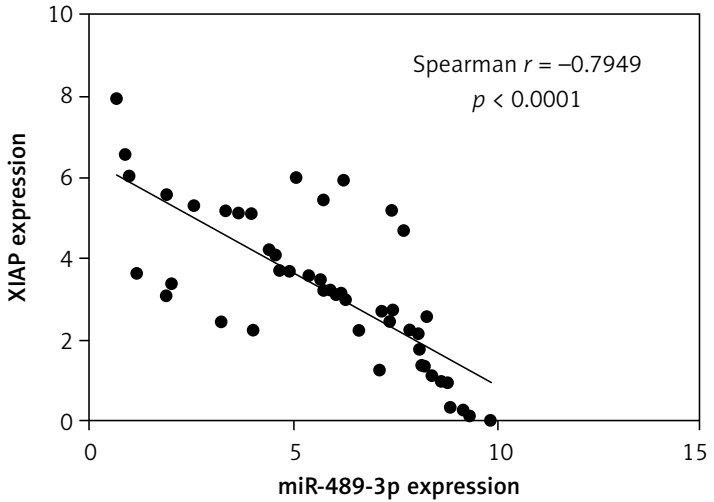

E

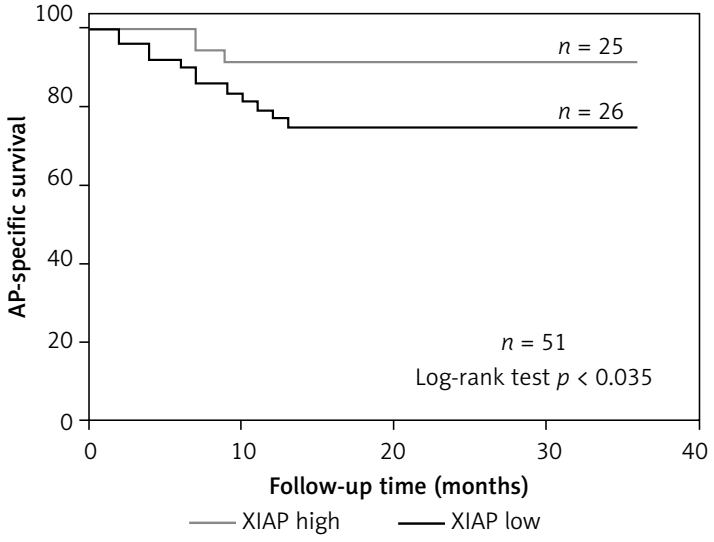

ered as statistical difference and $p<0.01$ as significant difference.

\section{Results}

Increased serum level of miR-489-3p in acute pancreatitis patients indicates poor prognosis

Comparison with non-AP patients showed that AP patients had increased serum level of miR-489$3 p$ (Figure $1 \mathrm{~A}, p<0.01$ ). The detection for serum expression of XIAP showed that XIAP was inhibited in AP patients compared with that in non-AP patients (Figure $1 \mathrm{~B}, p<0.01$ ). Correlation analysis showed that the expression of miR-489-3p

B

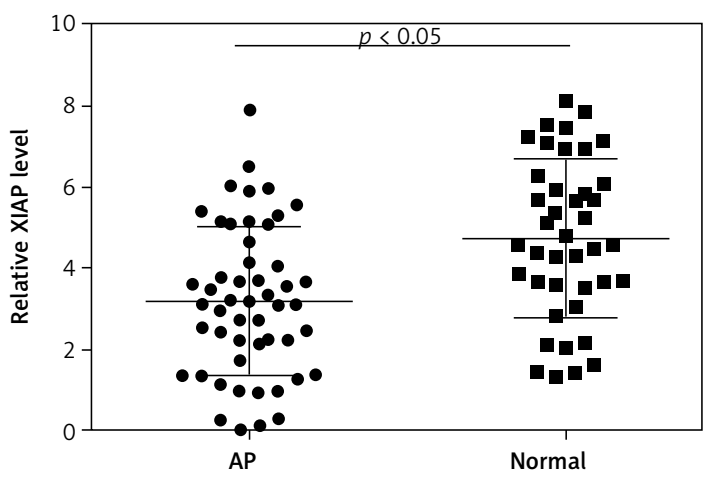

D

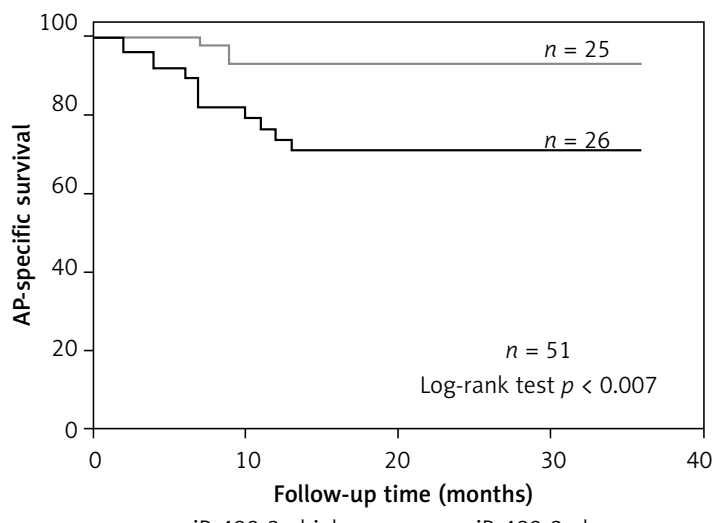

—miR-489-3p high miR-489-3p low

Figure 1. Detection of serum level of miR-489$3 p$ and $X$-linked inhibitor of apoptosis protein in patients with acute pancreatitis by quantitative polymerase chain reaction. Acute pancreatitis (AP) patients $(n=51)$ had increased serum level of miR489-3p (A) and decreased serum level of $X$-linked inhibitor of apoptosis protein (XIAP) (B) compared with patients who had bile duct stone but without AP $(n=40)$. Correlation analysis between miR-489$3 p$ expression and XIAP expression was demonstrated (C). The relationships of AP patient survival rates with miR-489-3p expression (D) and XIAP expression $(\mathrm{E})$ were presented

* $-p<0.05$ when compared with the normal group, patients had bile duct stone but without AP. 
was negatively correlated with XIAP (Figure $1 \mathrm{C}$, $p<0.01$ ). According to the expression level of miR-489-3p, AP patients were classified into an miR-489-3p high-expression group $(n=26)$ and an miR-489-3p low-expression group $(n=25)$. The analysis of the association between serum level of miR-489-3p and mortality of AP showed that increased serum level of miR-489-3p in AP is an indicator of poor prognosis (Figure $1 \mathrm{D}, p<0.01$ ). Based on the expression level of XIAP, AP patients were grouped into a XIAP high-expression group $(n=25)$ and XIAP low-expression group $(n=26)$. The prognosis analysis presented that AP patients with high expression of XIAP had a good prognosis indicating elevated serum level of XIAP in AP is an indicator of good prognosis (Figure $1 \mathrm{E}, p<$ 0.01 ). All data unfolded the indispensable roles of miR-489-3p and XIAP in AP.

\section{Up-regulated miR-489-3p and down- regulated $X$-linked inhibitor of apoptosis protein in cerulein-stimulated pancreatic AR42J cells}

In this study, we used $10^{-7} \mathrm{M}$ of cerulein to stimulate AR42J cells. MTT assay and FCM showed that cerulein can promote cell apoptosis and inhibit cell proliferation in AR42J cells (Figure $2 \mathrm{~A}-\mathrm{B}, p<$ 0.01). Enzyme-linked immunosorbent assay was also applied to verify inflammation by detection of inflammatory cytokines, including SAA, IL-1 $\beta$, IL6, and CRP. Enzyme-linked immunosorbent assay showed that cerulein can increase the expressions of SAA, IL-1 $\beta$, IL- 6 , and CRP. Those results collectively support the observation that cerulein can induce AP in AR42J cells (Figure $2 \mathrm{C}-\mathrm{E}, p<0.01$ ).

Then we used RT-PCR and western blot to detect the expressions of miR-489-3p and XIAP in cerulein-stimulated AR42J cells. The detection corroborated that cerulein can increase the mRNA expression of miR-489-3p (Figure $2 \mathrm{~F}, p<0.01$ ) while suppressing the mRNA and protein expressions of XIAP (Figure $2 \mathrm{G}-\mathrm{H}, p<0.01$ ) in AR42J cells. This evidence shows that miR-489-3p may regulate cell proliferation and apoptosis in AP cells by negatively regulating XIAP.

\section{MiR-489-3p promotes cell apoptosis and inhibits cell proliferation in cerulein- induced acute pancreatitis cells by regulating $X$-linked inhibitor of apoptosis protein}

After AR42J cells were stimulated by cerulein for $3 \mathrm{~h}$, cells were transfected with inhibitor NC, miR-489-3p inhibitor, mimic NC, or miR-489-3p mimic. AR42J cells in the control group were induced by cerulean. Then RT-PCR was applied to verify the transfection efficiency of miR-489-3p inhibitor and miR-489-3p mimic plasma $48 \mathrm{~h}$ after cell transfection. Reverse transcription polymerase chain reaction showed that transfection of miR-489-3p inhibitor can substantially suppress miR-489-3p expression (Figure $3 \mathrm{~A}, p<0.01$, vs. control group) but increase mRNA and protein expressions of XIAP, while transfection of miR489-3p mimic can increase miR-489-3p expression but suppress mRNA and protein expressions of XIAP (Figure $3 \mathrm{~B}-\mathrm{C}, p<0.01$, vs. control group). MTT on cell proliferation underlined that AR42 cells transfected with miR-489-3p inhibitor had increased cell proliferation while cells transfected with miR-489-3p mimic had suppressed the cell proliferation rate (Figure $3 \mathrm{D}, p<0.01$, vs. control group). Flow cytometry on cell apoptosis supported that cells transfected with miR-489-3p inhibitor had substantially inhibited cell apoptosis rate (Figure $3 \mathrm{E}, p<0.01$, vs. control group). In addition, western blot was applied to explore the role of miR-489-3p on apoptotic-related proteins, and it was found that cells transfected with miR-489-3p inhibitor had suppressed expressions of pro-apoptotic protein $\mathrm{p} 53$ and Bax, while transfection with miR-489-3p mimic could increase the expressions of p53 and Bax (Figure 3 F, $p<0.01$, vs. control group).

\section{MiR-489-3p inhibitor suppresses cell apoptosis and promotes cell proliferation in acute pancreatitis rat model by up- regulating $\mathrm{X}$-linked inhibitor of apoptosis protein}

Before rats were sacrificed, the physical and mental conditions of rats in all groups were monitored and the comparisons of condition of rats in each group showed no difference. Haematoxylin and eosin staining demonstrated that the morphologies of pancreatic tissues of rats injected with normal saline remain unchanged. The morphology of rats in the model group was presented with local necrosis, inflammatory cell infiltration of pancreatic mesenchyme, and unclear boundary. No haemorrhage or oedema was observed (Figure $4 \mathrm{~A}$ ). The serum levels of amylase and lipase were higher in the model group than in the normal group (Figure $4 \mathrm{~B}-\mathrm{C}, p<0.01$ ). The morphology changes in the model group suggest that the AP rat model was successfully established.

To further confirm the effect of miR-489-3p on cell proliferation and apoptosis in AP, we injected miR-489-3p inhibitor or inhibitor NC into AP rat models. Haematoxylin and eosin staining revealed that the rats injected with miR-489-3p inhibitor NC had more severed cell injury than those injected with miR-489-3p inhibitor (Figure 4 A, $p<0.01$ ). The measurement on miR-489-3p showed that rats injected with miR-489-3p inhibitor had lower 
A

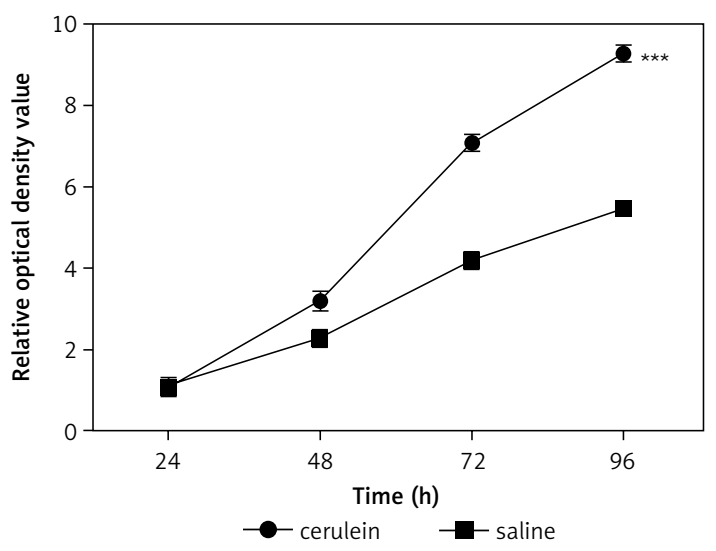

C

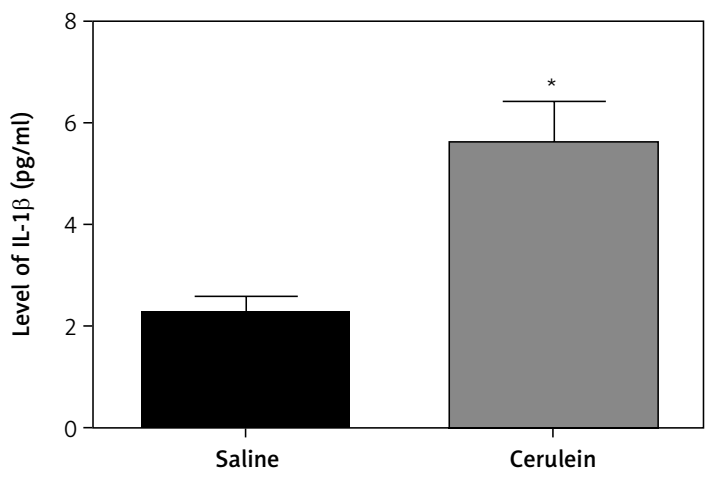

E

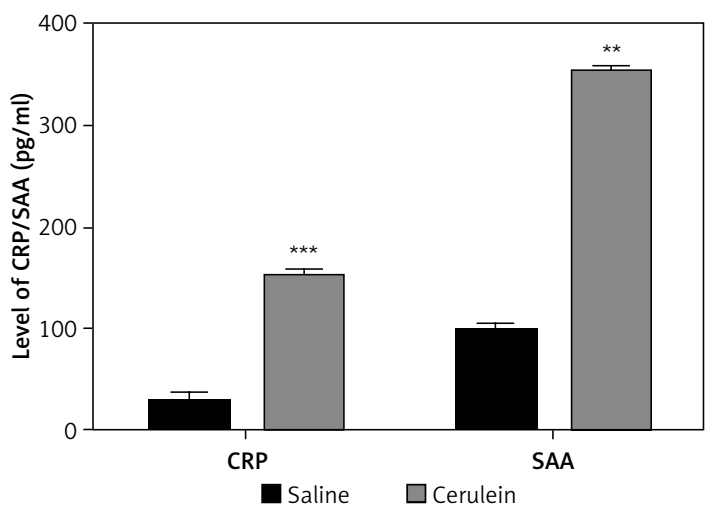

B
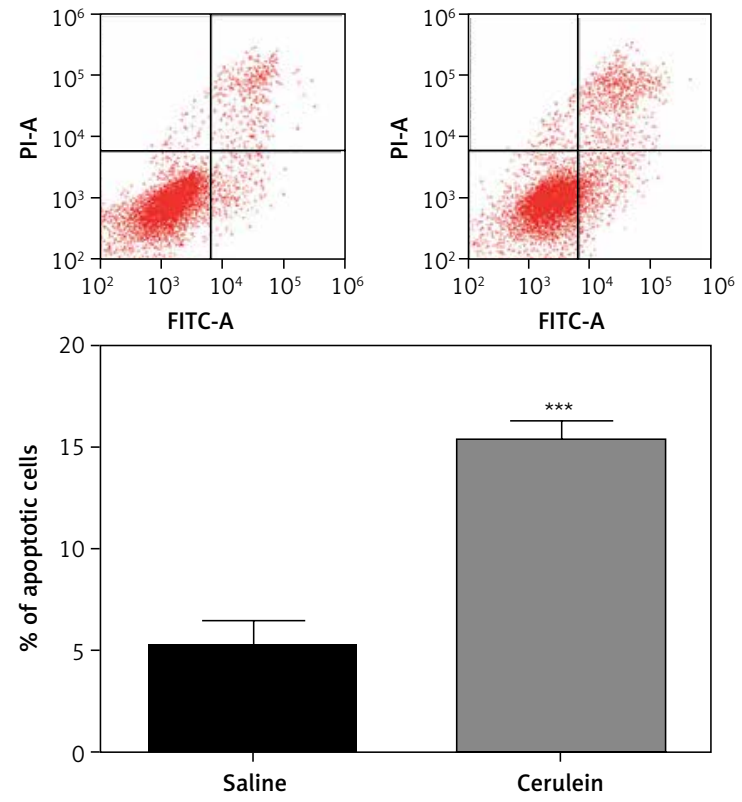

D

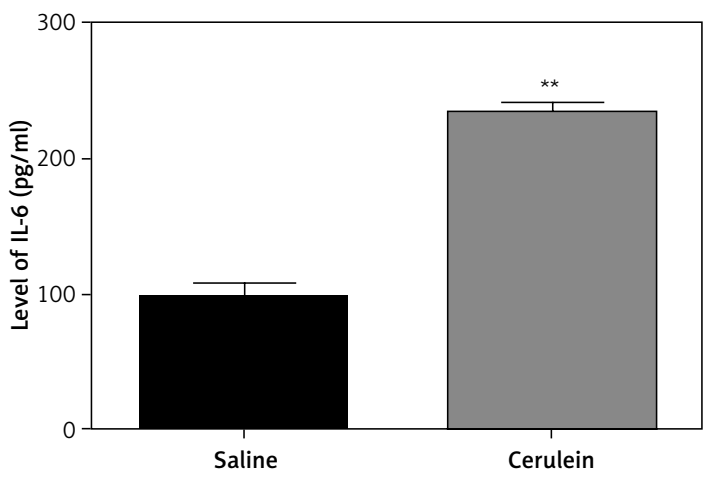

F

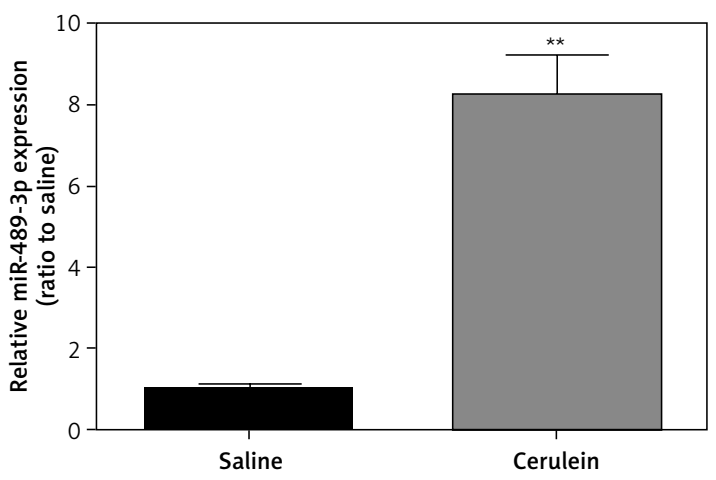

Figure 2. Expressions of miR-489-3p and X-linked inhibitor of apoptosis protein in cerulein-stimulated acute pancreatitis cells. Cerulein was used to stimulate pancreatic AR42J cells. MTT (A) and flow cytometry (B) were applied to investigate the effect of cerulein in cell proliferation and apoptosis. Cerulein was proven to promote the secretion of inflammatory cytokines, IL-1 $\beta$ (C), IL-6 (D), and c-reactive protein/serum amyloid A (E) by enzyme-linked immunosorbent assay. Reverse transcription polymerase chain reaction and western blot were applied to detect the expression of miR-489-3p (F) as well as mRNA (G) and protein (H) expressions of X-linked inhibitor of apoptosis protein

${ }^{*}-p<0.05,{ }^{* *},-p<0.01,{ }^{* *}-p<0.001$ when compared with the normal group: AR42J cells injected with normal saline. 
G

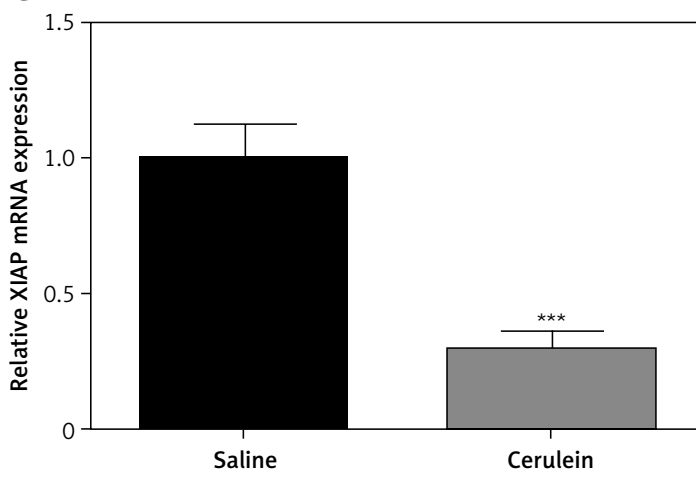

H

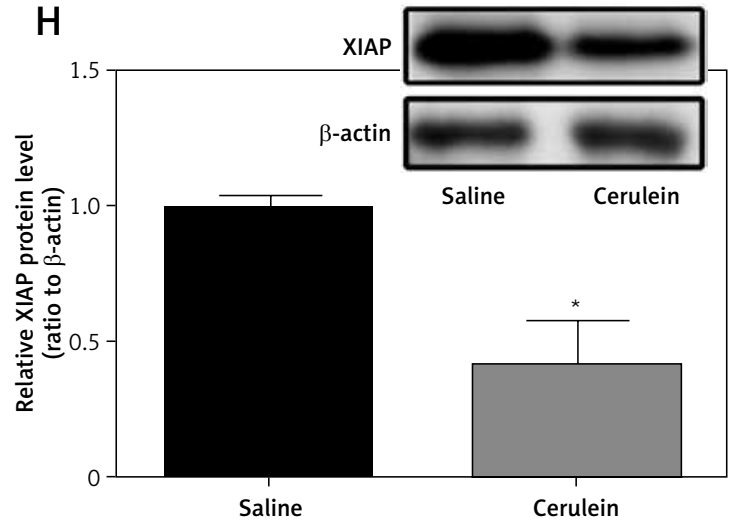

Figure 2. Cont. MTT (A) and flow cytometry (B) were applied to investigate the effect of cerulein in cell proliferation and apoptosis. Cerulein was proven to promote the secretion of inflammatory cytokines, IL-1 $\beta$ (C), IL-6 (D), and c-reactive protein/serum amyloid A (E) by enzyme-linked immunosorbent assay. Reverse transcription polymerase chain reaction and western blot were applied to detect the expression of miR-489-3p (F) as well as mRNA (G) and protein $(\mathbf{H})$ expressions of $\mathbf{X}$-linked inhibitor of apoptosis protein

${ }^{*}-p<0.05,{ }^{* *},-p<0.01,{ }^{* * *}-p<0.001$ when compared with the normal group: AR42J cells injected with normal saline.

miR-489-3p expression than those injected with inhibitor NC (Figure 4 D, $p<0.01$ ). Immunohistochemistry (IHC) staining showed that miR-489-3p inhibitor could elevate the expression of XIAP, as shown by higher XIAP-positive cell numbers in cells of rats injected with miR-489-3p inhibitor (Figure $4 \mathrm{E}, p<0.01$ ). Those results suggest that miR-489-3p inhibitor could partially reverse cell injury induced by cerulein and offset the elevated expression of miR-489-3p induced by cerulein. Then IHC was applied to detect the expression of proliferation biomarker $\mathrm{Ki}-67$, and the results showed that miR-489-3p inhibitor could substantially increase the expression of Ki-67, suggesting that miR-489-3p inhibitor can promote cell proliferation (Figure $4 \mathrm{~F}, p<0.01$ ). Western blot was also applied to measure XIAP and Ki67 in AP rat tissues, which showed that inhibition of miR-489$3 p$ could restore the expression of both XIAP and $\mathrm{Ki67}$ in AP rat tissue (Figure $4 \mathrm{G}, p<0.01$ ). Flow cytometry results implied that rats injected with miR-489-3p inhibitor had lower cell apoptosis than that with inhibitor NC (Figure $4 \mathrm{H}, p<0.01$ ). Meanwhile, transfection of miR-489-3p inhibitor can decrease the expressions of pro-apoptotic proteins (Bax and p53) (Figure $4 \mathrm{I}, p<0.01$ ). The assays and experiments on AP rat model suggested that miR-489-3p can promote cell apoptosis and inhibit cell proliferation by down-regulating XIAP.

\section{X-linked inhibitor of apoptosis protein is a target gene of miR-489-3p}

The bind site of miR-489-3p and XIAP was predicted by online software (Figure $5 \mathrm{~A}$ ). To confirm the putative targeting relationship between these two proteins, we constructed wild XIAP luciferase promoter plasma (named WT-XIAP) and mutant
XIAP luciferase promoter plasma (containing 13 mutant sites binding to miR-489-3p, named MTXIAP). Luciferase reporter gene assay showed that HEK-293 cells with co-transfection of miR-489-3p mimics and WT-XIAP had less luciferase activity than that transfected with mimics NC and WTXIAP $(p<0.01)$, while co-transfection of WT-XIAP and miR-489-3p inhibitor had increased luciferase activity $(p<0.01)$. However, no significance was detected between HEK-293 cells co-transfected with MT-XIAP and miR-489-3p inhibitor, and cells co-transfected with MT-XIAP and miR-489-3p mimics (Figure $5 \mathrm{~B}$ ). Then the targeting relationship between miR-489-3p and XIAP was verified by co-immunoprecipitation and immunoprecipitation reverse transcription polymerase chain reaction. Real-time PCR demonstrated that the expression of miR-489-3p of cells treated by XIAP antibody was higher than that treated with IgG antibody (Figure 5 C, $p<0.01$ ). Western blot showed that XIAP was highly expressed in RNA-protein complex (Figure $5 \mathrm{D}, p<0.01$ ). The above results implied that XIAP can directly bind to miR-489-3p.

\section{Discussion}

Acute pancreatitis consists of a complex chain reaction wherein acinar cell damage leads to a local and systemic inflammatory response in experimental and human AP [24]. However, the pathology of AP remains to be determined. The most well-known theory is the activation of trypsinogen, which involves sterile autodigestion by premature degrading enzymes results in acinar cell necrosis [25]. Along with the increasing research on AP, growing evidence for inflammatory factor theory has emerged for AP pathology [26]. Although more and more data have advanced our understanding of AP triggers, this disease has a high mortality, 
A

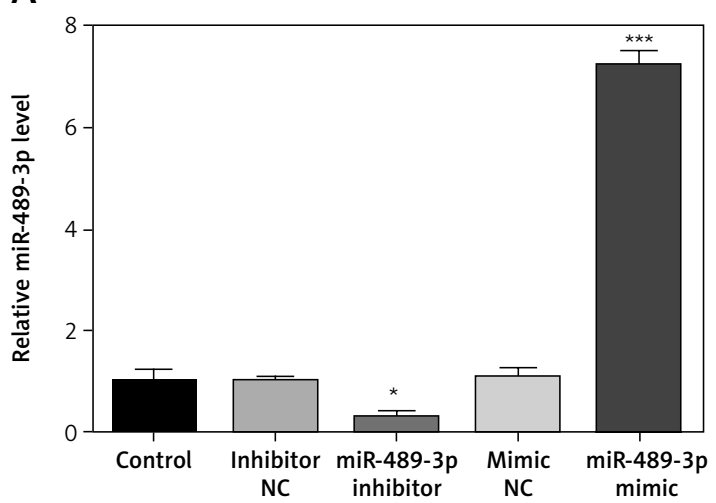

C
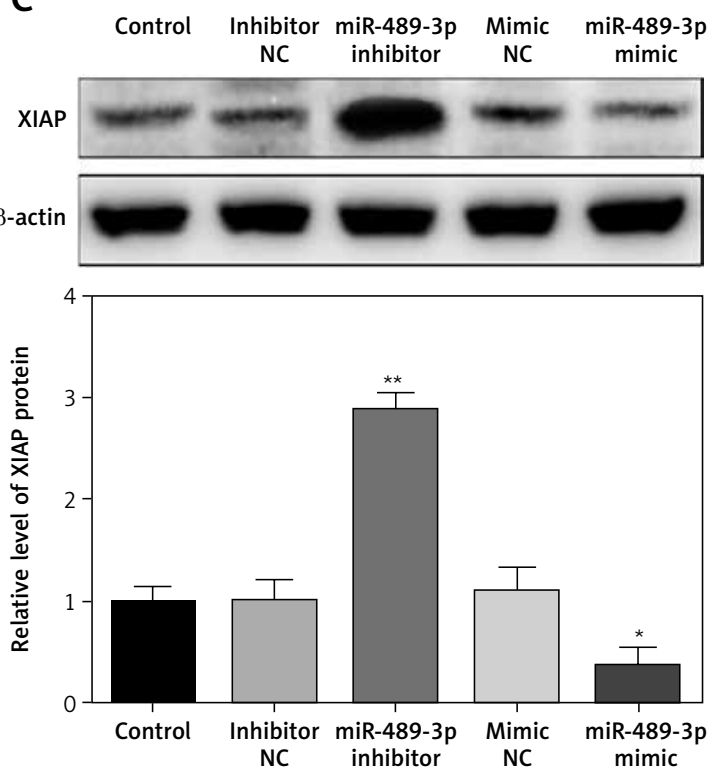

$E$
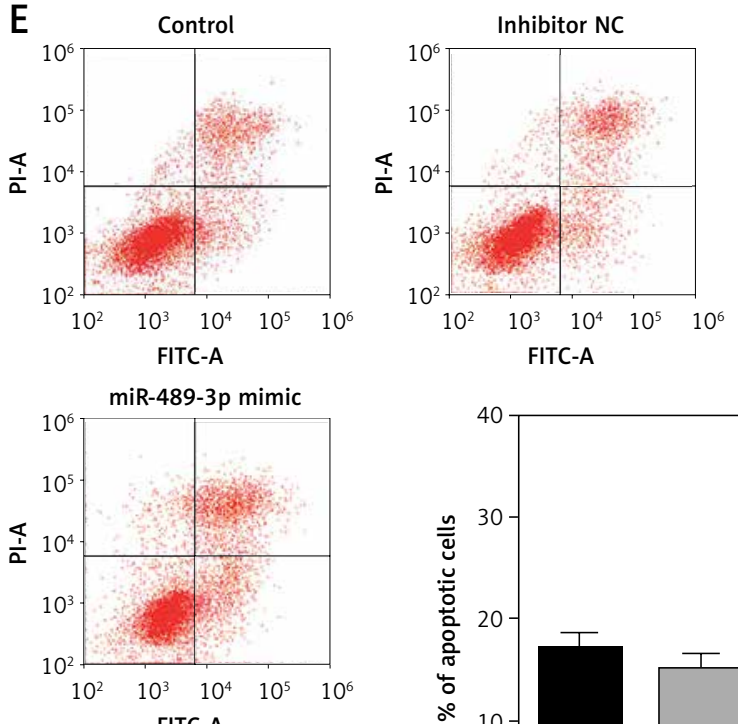

B

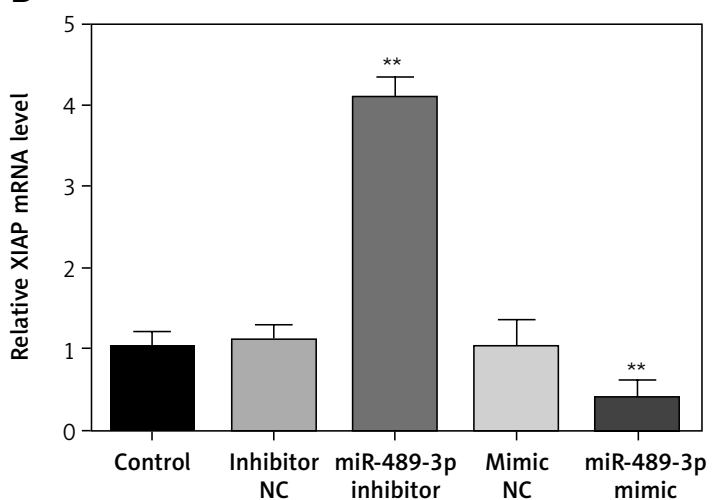

D

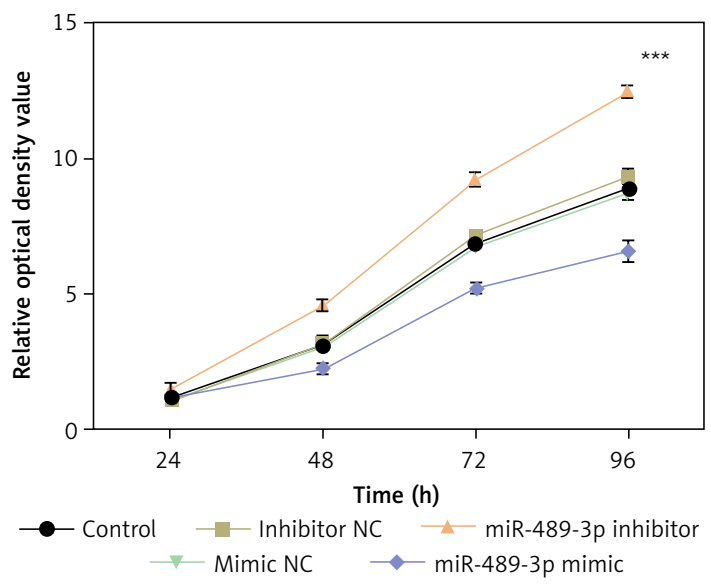

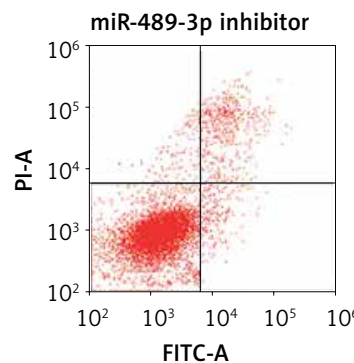
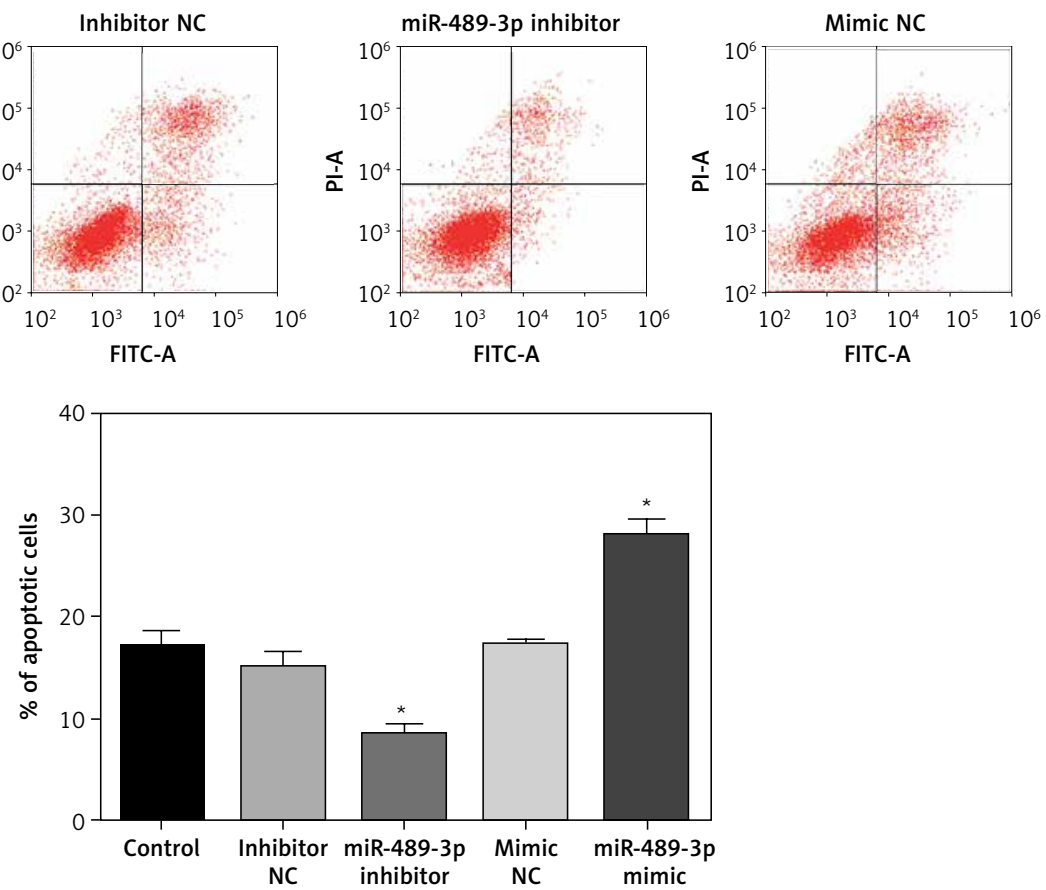

Figure 3. MiR-489-3p inhibits cell proliferation and promotes cell apoptosis in cerulein-stimulated acute pancreatitis cells by negatively regulating $X$-linked inhibitor of apoptosis protein. The transfection efficiency of plasma transfection into AR42J cells was verified by reverse transcription polymerase chain reaction (A). Reverse transcription polymerase chain reaction (B) and western blot (C) were used to measure the mRNA and protein expressions of X-linked inhibitor of apoptosis protein. Cell proliferation and apoptosis were correspondingly observed by MTT assay (D) and flow cytometry (E)

${ }^{*}-p<0.05,{ }^{* *}-p<0.01,{ }^{* *}-p<0.001$ when compared with the control group, NC - negative control, AP-acute pancreatitis. 


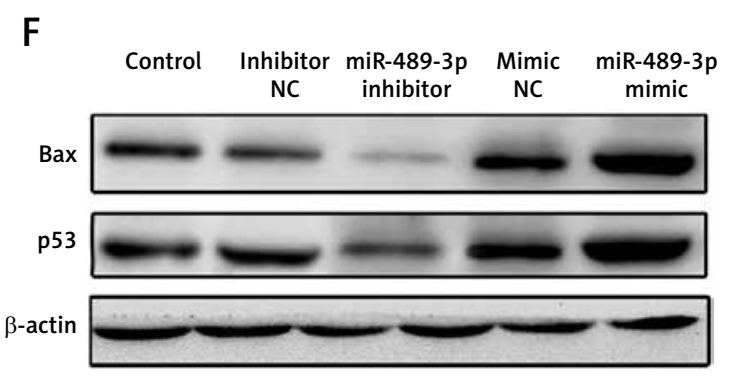

Figure 3. Cont. The expressions of pro-apoptotic proteins Bax and p53 were examined by western blot (F)

${ }^{*}-p<0.05,{ }^{* *}-p<0.01,{ }^{* * *}-p<0.001$ when compared with the control group, NC - negative control, AP - acute pancreatitis.

and investigations on prognostic evaluation of AP are encouraging $[11,27]$. In this study, we detected the expressions of miR-489-3p and XIAP in AP patients and cerulein-induced AR42J cells as well as in a cerulein-induced AP rat model. The assays and experiments in AR42J cells and AP rat models further supported the theory that miR-489-3p can promote cell apoptosis and inhibit cell proliferation in AP by negatively targeting XIAP.

Firstly, miR-489-3p was found to be up-regulated in AP patients, and patients with higher serum levels of miR-489-3p had a poor prognosis. Subsequently, miR-489-3p facilitated cell apoptosis and hampered cell proliferation in both AP cells and AP rat models. Similarity, miR-489 is reported as a tumour suppressor in various tumours. For example, the suppressive role of miR-489 in cell proliferation of breast cancer was reported in a previous study by Patel et al. [28]. Studies in gastric cancer and ovarian cancer showed that miR-489 overexpression inhibited cell proliferation and invasion but induced cell apoptosis by regulating its target genes $[29,30]$. The role of miR-489 in suppressing cell proliferation and promoting cell apoptosis was verified in inflammatory disease and malignant tumours [31]. Also, miR-489 was reported to be decreased in tumour cells, therefore miR-489 was originally identified to inhibit cell proliferation and promote cell apoptosis [17, 32]. However, the up-regulated expression of miR-489 in AP was inconsistent with its expression pattern in malignant tumours, in which miR-489 was sharply reduced in cancer tissues and cell lines [33]. The possible explanation may be that inflammation is a defence mechanism for the immune system response to harmful stimuli to remove injurious stimuli and initiate the healing process; therefore, we speculate that the differential expression of miR-489 in AP and in malignant tumours may result from the inflammatory stimuli. However, the mechanism underlying the influence of miR-489$3 p$ on AP progression has not been fully demonstrated.

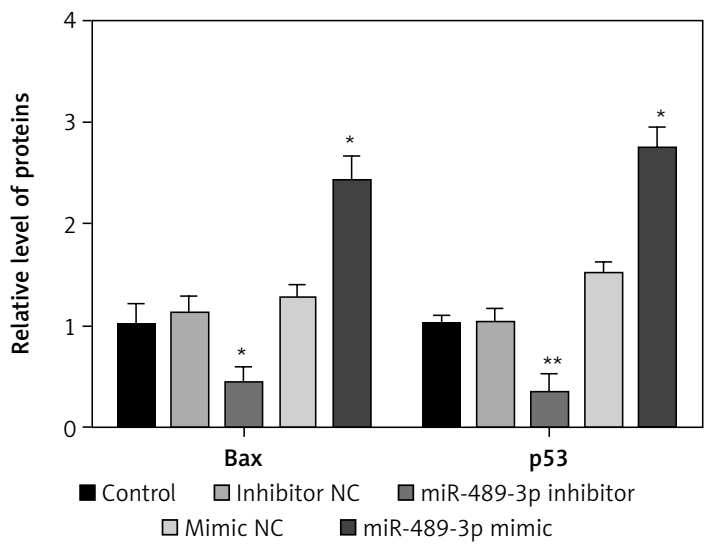

X-linked inhibitor of apoptosis protein, a potent anti-apoptotic protein, inhibits cell apoptosis after being stimulated by apoptotic signals [34]. Inhibition of XIAP represents a potential therapeutic strategy for the treatment of AP [35]. In this study, XIAP levels are diminished in AP cells. Correlation analysis between miR-489-3p and XIAP subsequently revealed a negative correlation between these two parameters. Then the target relationship is supported by luciferase reporter gene assay that miR-489-3p exerts its apoptosis promotion and proliferation inhibition function by down-regulating XIAP in AP. Similar results was obtained in breast cancer stem cells that miR-489 reverses 5 -FU resistance through the down-regulation of XIAP [36]. X-linked inhibitor of apoptosis protein contains three baculovirus inhibitor apoptosis protein repeat (BIR) domains and a RING zinc finger domain; the former is required to inhibit caspase pathway [37]. There are two main apoptotic pathways for regulating cell apoptosis in pancreatic acinar cells, including death receptor pathway and mitochondrial pathway, which can be trigged by members of the caspase family, thus by caspase- 8 and caspase-9, respectively [38]. Then the activated caspase- 8 and caspase- 9 can subsequently cleave and trigger other caspases, including caspase- 3 and caspase-7, consequently resulting in cell apoptosis [39]. The BIR 2 domain of XIAP can directly hinder the active site of caspase- 3 and caspase-7, while the BIR 3 domain of XIAP can block the activation of caspase-9 [35, 40]. Therefore, XIAP exerting its anti-apoptotic role in AP may be explained by its inhibition on caspase signal pathway. Collectively, our results elaborated that miR-489-3p can repress AP cell proliferation and facilitate cell apoptosis by targeting XIAP. The limitations of this study should also be mentioned. Although miR-489-3p was proven to promote cell apoptosis and inhibit cell proliferation in AP cells, the expression pattern of miR-489-3p detected in AP patients was inconsistent with the traditional expression pattern of miR-489-3p in 
A

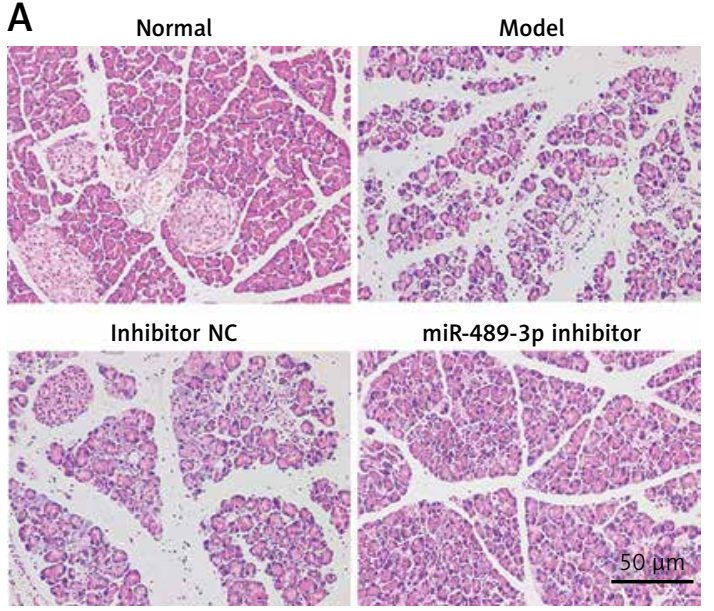

C

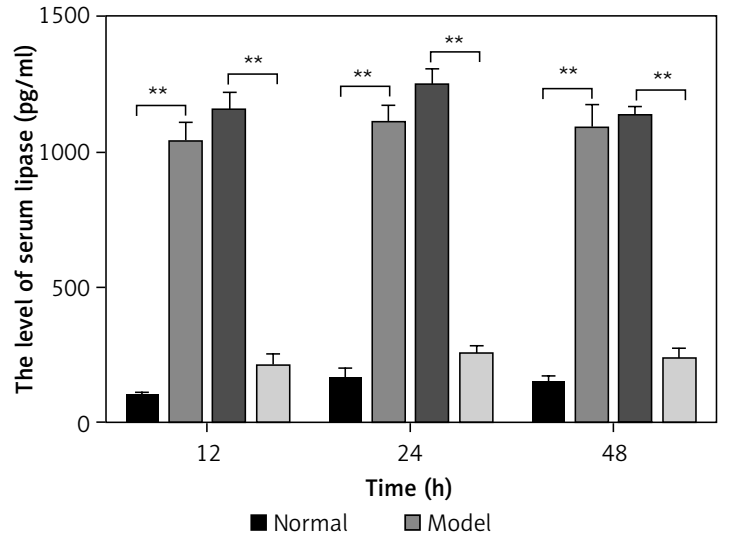

$\square$ Inhibitor NC $\quad \square$ miR-489-3p inhibitor

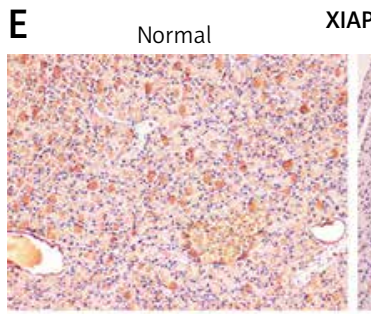

Inhibitor NC

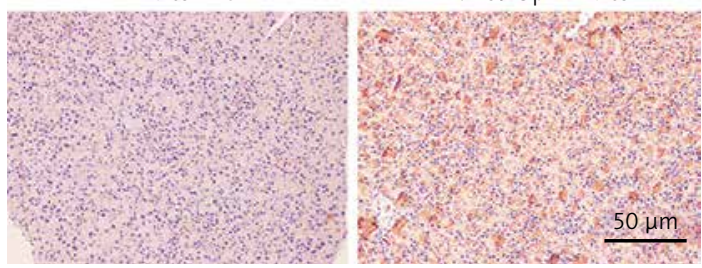

B

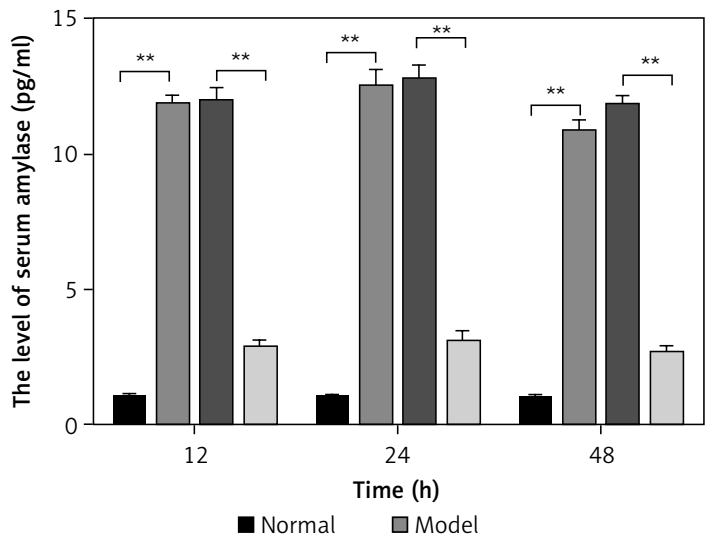

$\square$ Inhibitor NC $\square$ miR-489-3p inhibitor

D
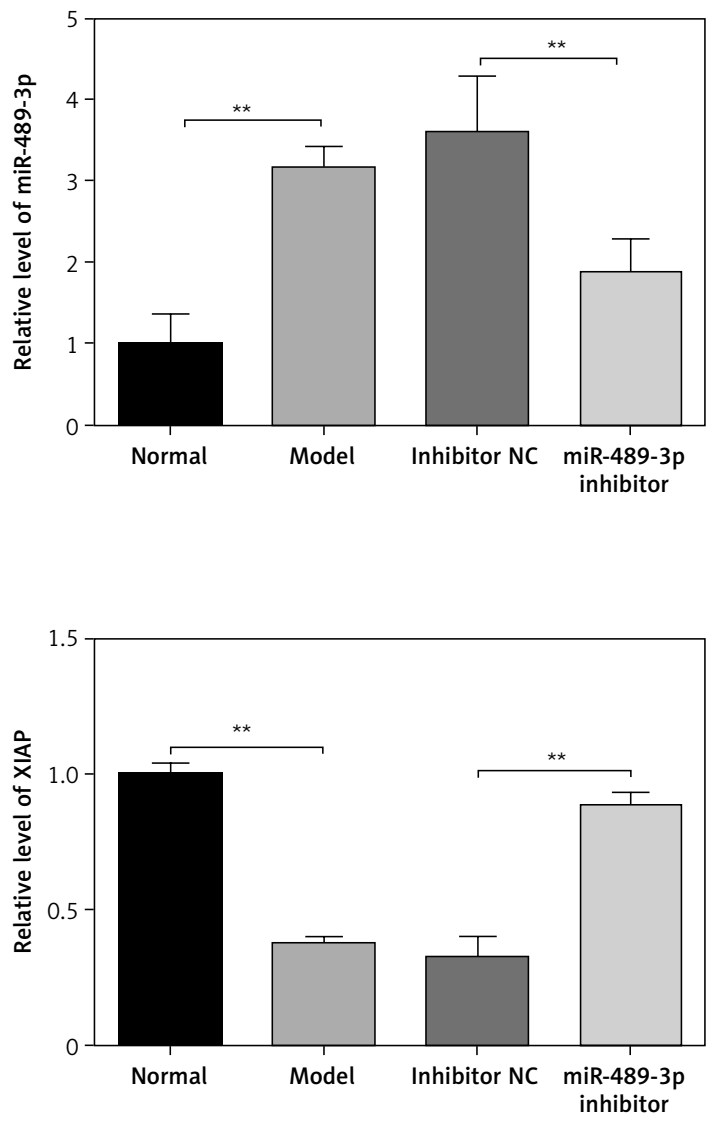

Figure 4. MiR-489-3p inhibitor can inhibits cell apoptosis and promote cell proliferation by down-regulating $X$-linked inhibitor of apoptosis protein in acute pancreatitis rat models. Pancreatic tissues from the rats in the experimental group were collected. Haematoxylin and eosin staining showed that morphology of rats injected with miR-489-3p inhibitor was much better than that with inhibitor negative control (inhibitor NC) (A). Olympus Au2700 system was used for measuring serum amylase level (B), and modular P800 automatic biochemical analyser for serum lipase level (C). Reverse transcription polymerase chain reaction (D) and immunohistochemistry (E-F) were utilised to detect the expressions of miR-489-3p, X-linked inhibitor of apoptosis protein (XIAP), and Ki-67

${ }^{*}-p<0.05,{ }^{* *}-p<0.01$ when compared with the normal group or inhibitor NC group, normal group - rats injected with normal saline, AP-acute pancreatitis. 

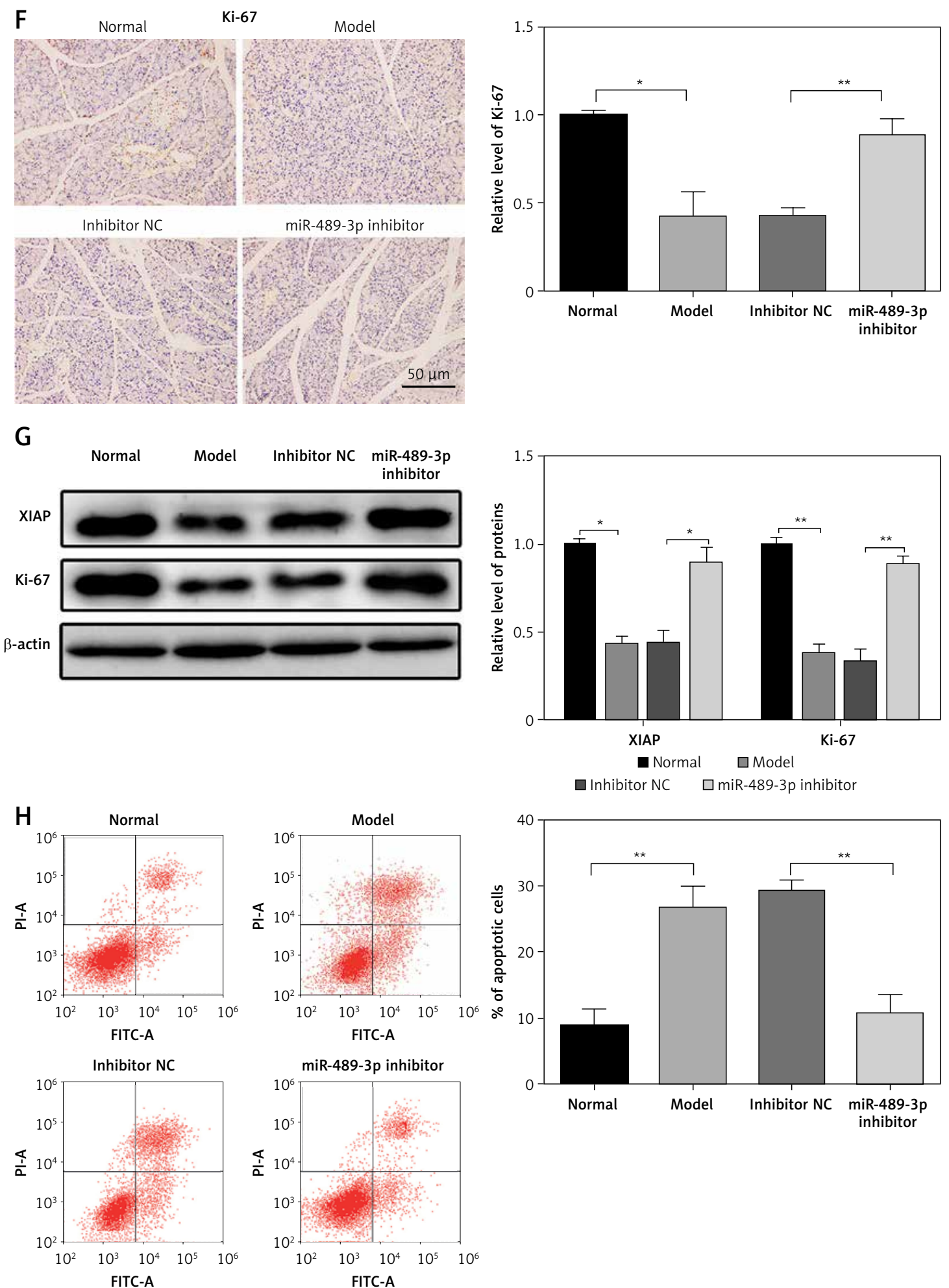

Figure 4. Cont. Immunohistochemistry (E-F) were utilised to detect the expressions of miR-489-3p, $X$-linked inhibitor of apoptosis protein (XIAP), and Ki-67. Scare Bar indicates $50 \mu \mathrm{m}$. Cell apoptosis was inspected by flow cytometry (H). Western blot was employed to exhibit the expressions of XIAP, Ki-67 (G)

${ }^{*}-p<0.05,{ }^{* *}-p<0.01$ when compared with the normal group or inhibitor NC group, normal group - rats injected with normal saline, $A P$ - acute pancreatitis. 

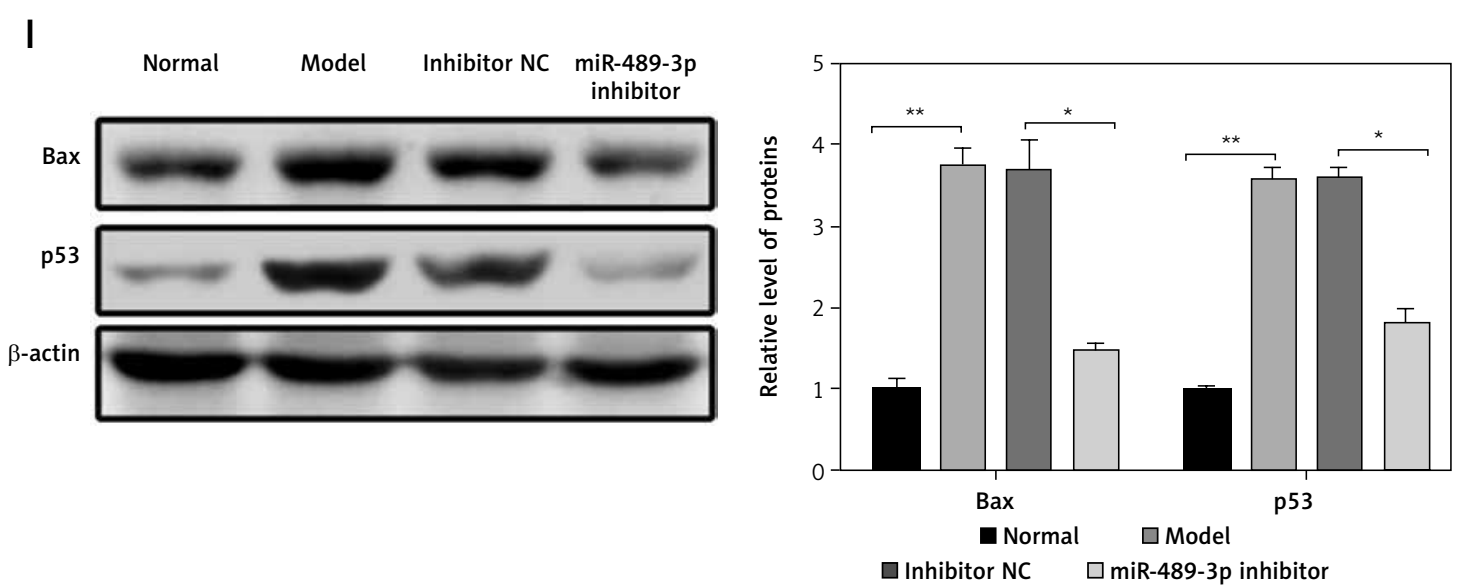

Figure 4. Cont. Pro-apoptotic proteins (I).

${ }^{*}-p<0.05,{ }^{* *}-p<0.01$ when compared with the normal group or inhibitor NC group, normal group - rats injected with normal saline, $A P$ - acute pancreatitis.

A

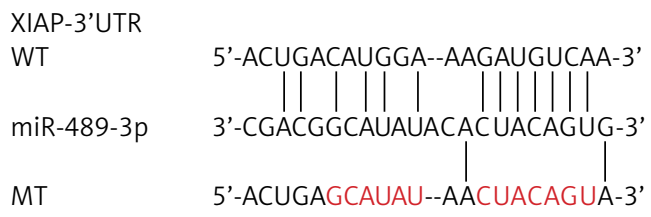

c

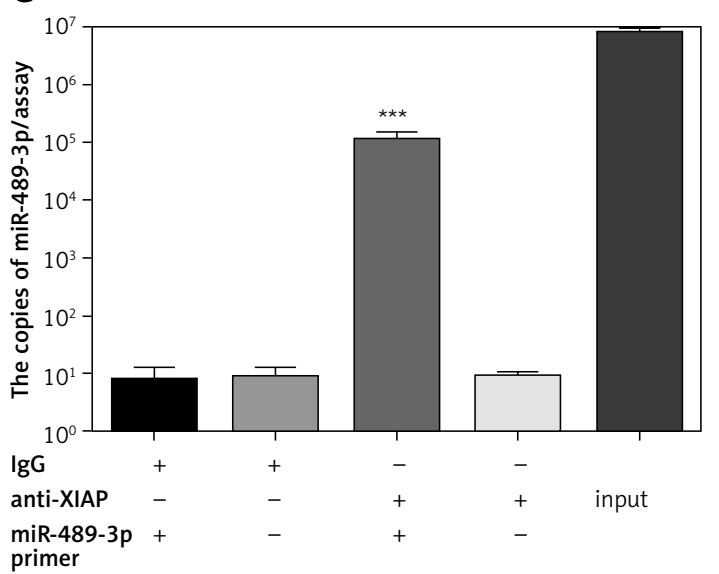

B

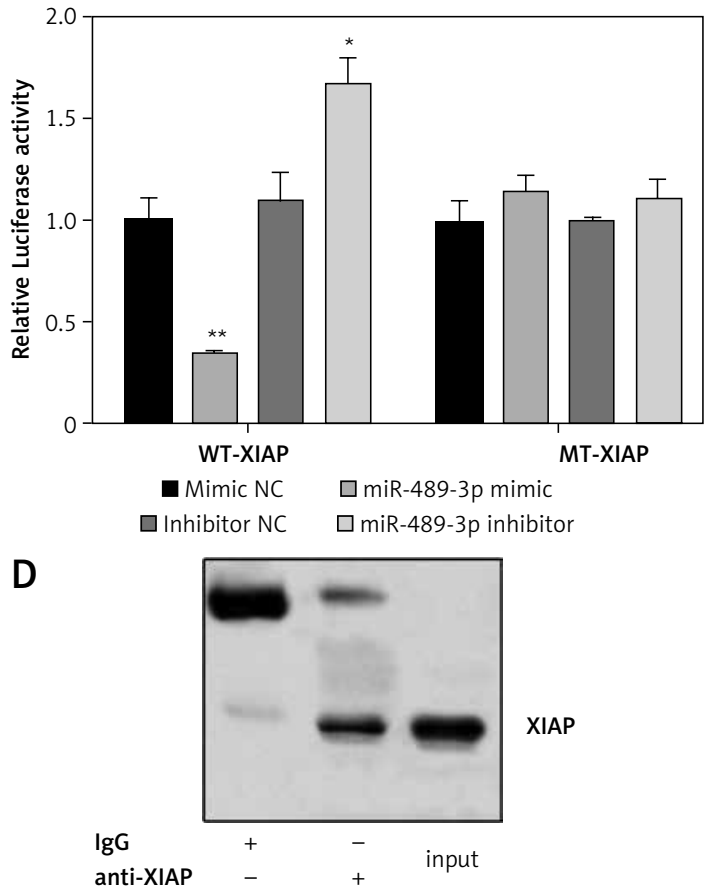

Figure 5. MiR-489-3p can directly target X-linked inhibitor of apoptosis protein. Online software predicted the bind site of miR-489-3p and X-linked inhibitor of apoptosis protein (XIAP) and XIAP sequence (A). After human embryonic kidney 293 cells were co-transfected with WT-XIAP or MT-XIAP and miR-489-3p mimic or miR-489-3p inhibitor for $48 \mathrm{~h}$, luciferase reporter gene assay was performed to detect luciferase activity (B). Immunoprecipitation reverse transcription polymerase chain reaction was performed to measure the expression of miR-489-3p in RNA-protein complex (C) and western blot was used to determine the expression of XIAP in RNA-protein complex (D)

${ }^{*}-p<0.05,{ }^{* *}-p<0.01,{ }^{* * *}-p<0.001$ when compared with NC group: negative control.

malignant tumours. Thus, the expression of miR489-3p in AP patients should be further verified in future studies despite the difficulty in obtaining human pancreatic samples. Nonetheless, results concluded from AP rat models and AP cells in this study were strongly grounded.

In conclusion, our study demonstrated that increased serum level of miR-489-3p is an indicator for poor prognosis of AP. In addition, miR-489-3p promotes cell apoptosis and inhibits cell proliferation in AP by down-regulating XIAP. Although we measured the expressions of miR-489-3p and XIAP in AP patients, AP cells, and AP rat models, further verification is still needed to verify our results and to advance our understanding of AP pathogenesis. 


\section{Acknowledgement}

This work was supported by the study of the mechanism of mir-439-3p targeting XIAP in the progression of acute pancreatitis (B2019068). We are grateful for all the support and contributions of participants.

\section{Conflict of interest}

The authors declare no conflict of interest.

\section{References}

1. Greenberg JA, Hsu J, Bawazeer M, et al. Clinical practice guideline: management of acute pancreatitis. Can J Surg 2016; 59: 128-40.

2. Kambhampati S, Park W, Habtezion A. Pharmacologic therapy for acute pancreatitis. World J Gastroenterol 2014; 20: 16868-80.

3. Jagielski $M$, Smoczynski $M$, Studniarek $M$, Adrych $K$. Spontaneous regression of asymptomatic walled-off pancreatic necrosis. Arch Med Sci 2019; 15: 1278-87.

4. Bortolotti P, Saulnier F, Colling D, Redheuil A, Preau S. New tools for optimizing fluid resuscitation in acute pancreatitis. World J Gastroenterol 2014; 20: 16113-22.

5. Karakayali FY. Surgical and interventional management of complications caused by acute pancreatitis. World J Gastroenterol 2014; 20: 13412-23.

6. Zhang J, Shahbaz M, Fang R, et al. Comparison of the BISAP scores for predicting the severity of acute pancreatitis in Chinese patients according to the latest Atlanta classification. J Hepatobiliary Pancreat Sci 2014; 21: 689-94.

7. Yang CJ, Chen J, Phillips AR, Windsor JA, Petrov MS. Predictors of severe and critical acute pancreatitis: a systematic review. Dig Liver Dis 2014; 46: 446-51.

8. Dervenis Ch. Assessments of severity and management of acute pancreatitis based on the Santorini Consensus Conference report. J Pancreas 2016; 1: 178-82.

9. Cho JH, Kim TN, Chung HH, Kim KH. Comparison of scoring systems in predicting the severity of acute pancreatitis. World J Gastroenterol 2015; 21: 2387-94.

10. Staubli SM, Oertli D, Nebiker CA. Laboratory markers predicting severity of acute pancreatitis. Crit Rev Clin Lab Sci 2015; 52: 273-83.

11. Meher S, Mishra TS, Sasmal PK, et al. Role of biomarkers in diagnosis and prognostic evaluation of acute pancreatitis. J Biomark 2015; 2015: 519534.

12. Joglekar MV, Parekh VS, Hardikar AA. Islet-specific microRNAs in pancreas development, regeneration and diabetes. Indian J Exp Biol 2011; 49: 401-8.

13. Wang J, Raimondo M, Guha S, et al. Circulating microRNAs in pancreatic juice as candidate biomarkers of pancreatic cancer. J Cancer 2014; 5: 696-705.

14. Schultz NA, Dehlendorff C, Jensen BV, et al. MicroRNA biomarkers in whole blood for detection of pancreatic cancer. JAMA 2014; 311: 392-404.

15. Alexander M, Hu R, Runtsch MC, et al. Exosome-delivered microRNAs modulate the inflammatory response to endotoxin. Nat Commun 2015; 6: 7321.

16. Buranjiang G, Kuerban R, Abuduwanke A, Li X, Kuerban G. MicroRNA-331-3p inhibits proliferation and metastasis of ovarian cancer by targeting RCC2. Arch Med Sci 2019; 15: 1520-9.

17. Li Y, Ma X, Wang Y, Li G. miR-489 inhibits proliferation, cell cycle progression and induces apoptosis of glioma cells via targeting SPIN1-mediated PI3K/AKT pathway. Biomed Pharmacother 2017; 93: 435-43.

18. Yuan P, He XH, Rong YF, et al. KRAS/NF-kappaB/YY1/miR489 signaling axis controls pancreatic cancer metastasis. Cancer Res 2017; 77: 100-11.

19. Liu P, Xia L, Zhang WL, et al. Identification of serum microRNAs as diagnostic and prognostic biomarkers for acute pancreatitis. Pancreatology 2014; 14: 159-66.

20. Beser OF, Conde CD, Kutlu T, et al. Inflammatory bowel disease with lethal disease course caused by a nonsense mutation in BIRC4 encoding X-Linked inhibitor of apoptosis protein (XIAP). J Pediatr Gastroenterol Nutr 2016; 62: e41-3.

21. Aguilar C, Latour S. X-linked inhibitor of apoptosis protein deficiency: more than an X-linked lymphoproliferative syndrome. J Clin Immunol 2015; 35: 331-8.

22. Gao J, Cui JZ, Wang A, et al. The reduction of XIAP is associated with inflammasome activation in RPE: implications for AMD pathogenesis. J Neuroinflammation 2019; 16: 171

23. Liu Y, Zhou ZG, Zhou B, et al. Downregulation of GRP78 and XIAP is correlated with apoptosis during cerulein-induced acute pancreatitis in rats via regulation of caspase activation. Mol Med Rep 2013; 7: 725-30.

24. Tariq S, Garg A, Gass A, Aronow WS. Myocarditis due to systemic lupus erythematosus associated with cardiogenic shock. Arch Med Sci 2018; 14: 460-62.

25. Dawra R, Sah RP, Dudeja V, et al. Intra-acinar trypsinogen activation mediates early stages of pancreatic injury but not inflammation in mice with acute pancreatitis. Gastroenterology 2011; 141: 2210-7 e2.

26. Sah RP, Dawra RK, Saluja AK. New insights into the pathogenesis of pancreatitis. Curr Opin Gastroenterol 2013; 29: 523-30.

27. Sigounas DE, Tatsioni A, Christodoulou DK, Tsianos EV, loannidis JP. New prognostic markers for outcome of acute pancreatitis: overview of reporting in 184 studies. Pancreas 2011; 40: 522-32.

28. Patel Y, Shah N, Lee JS, et al. A novel double-negative feedback loop between miR-489 and the HER2-SHP2MAPK signaling axis regulates breast cancer cell proliferation and tumor growth. Oncotarget 2016; 7: 18295-308.

29. Zhang B, Ji S, Ma F, et al. miR-489 acts as a tumor suppressor in human gastric cancer by targeting PROX1. Am J Cancer Res 2016; 6: 2021-30.

30. Wu H, Xiao Z, Zhang H, et al. MiR-489 modulates cisplatin resistance in human ovarian cancer cells by targeting Akt3. Anticancer Drugs 2014; 25: 799-809.

31. Yang L, Karin M. Roles of tumor suppressors in regulating tumor-associated inflammation. Cell Death Differ 2014; 21: 1677-86

32. Xie Z, Cai L, Li R, et al. Down-regulation of miR-489 contributes into NSCLC cell invasion through targeting SUZ12. Tumour Biol 2015; 36: 6497-505.

33. Li J, Qu W, Jiang Y, et al. miR-489 Suppresses proliferation and invasion of human bladder cancer cells. Oncol Res 2016; 24: 391-8.

34. Gyrd-Hansen M, Meier P. IAPs: from caspase inhibitors to modulators of NF-kappaB, inflammation and cancer. Nat Rev Cancer 2010; 10: 561-74.

35. Liu Y, Chen XD, Yu J, et al. Deletion Of XIAP reduces the severity of acute pancreatitis via regulation of cell death and nuclear factor-kappaB activity. Cell Death Dis 2017; 8: e2685.

36. Wang X, Wang X, Gu J, et al. Overexpression of miR-489 enhances efficacy of 5-fluorouracil-based treatment in breast cancer stem cells by targeting XIAP. Oncotarget 2017; 8: 113837-46. 
37. Pang Y, Mao H, Shen L, et al. MiR-519d represses ovarian cancer cell proliferation and enhances cisplatin-mediated cytotoxicity in vitro by targeting XIAP. Onco Targets Ther 2014; 7: 587-97.

38. Zhang M, Harashima N, Moritani T, Huang W, Harada M. The roles of ROS and caspases in TRAIL-induced apoptosis and necroptosis in human pancreatic cancer cells. PLoS One 2015; 10: e0127386.

39. Lomberk G, Urrutia R. Primers on molecular path ways-caspase pathway. Pancreatology 2009; 9: 6-8.

40. Yabal M, Muller N, Adler H, et al. XIAP restricts TNF- and RIP3-dependent cell death and inflammasome activation. Cell Rep 2014; 7: 1796-808. 